\title{
Studies on the Biology of Schistosomiasis with Emphasis on the Senegal River Basin
}

\author{
VR Southgate ${ }^{+}{ }^{,}$L-A Tchuem Tchuenté*, M Sène**, D De Clercq***, \\ A Théron****, J Jourdane ${ }^{* * * *}$, BL Webster, D Rollinson, B Gryseels*****, \\ J Vercruysse $\mathrm{e}^{* * * * * *}$
}

\begin{abstract}
Biomedical Sciences Theme, Department of Zoology, The Natural History Museum, Cromwell Road, London SW7 5BD, UK *The University of Yaoundé, Cameroon **IRD (ex ORSTOM), Bel Air, Dakar, Senegal ***Programme Espoir, St Louis, Senegal ****Laboratoire de Biologie Animale, Université, Perpignan, France ******Institute of Tropical Medicine, Antwerp, Belgium *******aculty of Veterinary Medicine, Merelbeke, Belgium
\end{abstract}

The construction of the Diama dam on the Senegal river, the Manantali dam on the Bafing river, Mali and the ensuing ecological changes have led to a massive outbreak of Schistosoma mansoni in Northern Senegal, associated with high intensity of infections, due to intense transmission, and the creation of new foci of S. haematobium. Data on the vectorial capacity of Biomphalaria pfeifferi from Ndombo, near Richard Toll, Senegal are presented with sympatric and allopatric (Cameroon) S. mansoni. Comparisons are made on infectivity, cercarial production, chronobiology of cercarial emergence and longevity of infected snails. Recent data on the intermediate host specificity of different isolates of S. haematobium from the Lower and Middle Valley of the Senegal river basin (SRB) demonstrate the existence of at least two strains of $\mathrm{S}$. haematobium. The role of Bulinus truncatus in the transmission of $\mathrm{S}$. haematobium in the Lower and Middle Valleys of the SRB is reviewed. Both $\mathrm{S}$. haematobium and $\mathrm{S}$. mansoni are transmitted in the same foci in some areas of the SRB.

Key words: Schistosoma mansoni - Schistosoma haematobium - Biomphalaria pfeifferi - Senegal river basin

The construction of the Diama dam (barrage) on the Senegal river basin (SRB) in 1985 to prevent the intrusion of sea water in the dry season to the environs of Richard Toll, and the dam at Manantali, in 1989 on the Bafing river, Mali, a tributary of the Senegal river, to control the flow of the river and eventually to generate electricity has resulted in marked ecological changes (Southgate 1997). The purpose of constructing the Diama dam was to reduce levels of salinity in the Senegal river thereby making the river water suitable for purposes of irrigation, primarily to increase the production of rice and sugar cane, and to mitigate against the food shortages that were experienced in the droughts of the 1970s. Hence, since the completion of the dams

This work received financial support from the European Commission INCO-DC (IC18-CT 96-0041) (IC18.CT 96-0112). BL Webster was in receipt of an MRC studentship.

+Corresponding author. Fax: +442079425518. E-mail: V.Southgate@nhm.ac.uk

Received 14 May 2001

Accepted 25 July 2001 there has been a huge increase in the numbers of hectares of rice under cultivation; also, there have been concomitant ecological changes in the SRB. The Manantali dam maintains a more stable flow, consequently the river is not subjected to sudden changes of water level. Fluctuations were up to 13 $\mathrm{m}$ per annum prior to the Manantali dam. The $\mathrm{pH}$ of the river water has changed from a slightly acidic environment ( $\mathrm{pH} 6.0$ or less) to a more alkaline environment ( $\mathrm{pH}$ 7.5-8.5). The reasons for the apparent change in $\mathrm{pH}$ are not fully understood. However, it is evident that these man made ecological changes have had an enormous impact on the prevalence, intensity and distribution of human schistosomiasis, especially in the Lower and Middle valleys of the SRB, and perhaps on veterinary schistosomiasis too, although there are not sufficient data to reach a firm conclusion on this aspect. More data on the prevalence and intensities of 'veterinary schistosomes', that is, infections of Schistosoma bovis and S. curassoni, are urgently required to enable the changing patterns of prevalence and intensity to be assessed.

Prior to the construction of the dams all villages in the 'walo' had low levels of urinary schistosomiasis (Chaine \& Malek 1983). Cisse et al. (1983) found no cases of S. haematobium in the village in 
the environs of Lac de Guiers where Bulinus truncatus was abundant. Southgate et al. (1985) reported S. haematobium in the Lower valley to be incompatible with B. truncatus, Vercruysse et al. (1985) showed that the prevalences of $S$. haematobium were much higher in the 'diéri' and two 'walo' villages, Lampsar and Guédé Chantier, than in the remainder of the 'walo' villages. It was originally considered that the comparatively high prevalences were associated with rice cultivation and the presence of the intermediate host $B$. senegalensis, yet, subsequent studies by Belot et al. (1993) and Picquet et al. (1996) failed to confirm the presence of $B$. senegalensis in the vicinity of Lampsar. It is probable that $B$. globosus is the intermediate host around Lampsar. B. globosus is sensitive to low levels of salinity, but small barrages had been built 60 years earlier on the Lampsar marigot to prevent sea water intrusion, thereby allowing the water to be used for public consumption in St Louis and irrigation. The reduction in levels of salinity has allowed B. globosus (a good intermediate host for some strains of $S$. haematobium) to become established. The feasibility study showed that the levels of $S$. haematobium in the delta were at a low level, and mesenteric schistosomiasis (S. mansoni) was not evident (Miller 1982). It was considered that the mean daily temperatures of $30^{\circ} \mathrm{C}$ or higher prevented the establishment of viable populations of Biomphalaria pfeifferi, thereby explaining the absence of mesenteric schistosomiasis in the area. However, eggs of $S$. mansoni were first noted in a stool examination in 1988 at Richard Toll (Talla et al. 1990), and a community based project in 1990 in Richard Toll showed that $60 \%$ of the subjects examined were positive (Talla et al. 1992). Malacological field studies demonstrated that $B$. pfeifferi represented approximately $70 \%$ of all freshwater snails collected at three different sites in the environs of Richard Toll (Talla et al. 1990), and the overall infection rate in B. pfeifferi represented was $44 \%$ (Diaw et al. 1990). B. pfeifferi has extended its range from the Lower Valley to Dagana, but has not reached Podor yet. Picquet et al. (1996) recorded mean intensities of 1,793 $\pm 848 \mathrm{epg}$ in the population in the vicinity of Lac de Guiers. More recently, De Clercq et al. (1999) have observed mean intensities of 589 eggs/g, with $35 \%$ of individuals excreting $>1,000$ eggs/g.

These high prevalences and intensities of infection, established in such a short period, indicate intense transmission. Tchuem Tchuenté et al. (1999) and Southgate et al. (2000) conducted detailed experiments to evaluate levels of snail-parasite compatibility, cercarial production, chronobiology (cercarial emergence rhythms), and snail mortality with
S. mansoni from Ndiangue, near Richard Toll, Senegal and Nkolbisson, Cameroon with B. pfeifferi from Senegal. The aim of the studies was to evaluate whether the sympatric intermediate host-parasite relationship with $S$. mansoni Senegal and $B$. pfeifferi Senegal was more compatible than the allopatric intermediate host parasite relationship $S$. mansoni Cameroon and B. pfeifferi Senegal. The results showed that for $S$. mansoni Senegal and $B$. pfeifferi Senegal $87 \%$ of the B. pfeifferi exposed to a single miracidium (MD1) became infected, and all surviving snails exposed to five miracidia (MD5) were positive, whereas for the $S$. mansoni Cameroon and B. pfeifferi Senegal, only $56.3 \%$ and $91.6 \%$ became positive for MD1 and MD5, respectively. For S. mansoni Senegal and B. pfeifferi Senegal the total production of cercariae per snail ranged from 18 , 703 to 73, 446, with a mean of 51, 692 for MD1 and 49,121 for MD5, which compared very favourably with a mean of 18,511 for MD1 and 9, 757 cercariae for MD5 for $S$. mansoni Cameroon and B. pfeifferi Senegal. The median for $S$. mansoni Senegal and $B$. pfeifferi Senegal was 533 cercariae per snail each day which was more than double the median of 233 cercariae per snail from S. mansoni Cameroon and B. pfeifferi Senegal. The maximum life span for an individual infected snail was 239 days p.i. (group MD1), and 237 days p.i. (group MD5) for S. mansoni Senegal and B. pfeifferi Senegal, which was considerably longer than 202 days p.i. and 178 days p.i., respectively, recorded for $S$. mansoni Cameroon and B. pfeifferi Senegal. The chronobiological data for both host/parasite combinations demonstrate that there is clearly only one peak of cercarial emission, around mid-day (Tchuem Tchuenté et al. 1999, Southgate et al. 2000). These data show that the sympatric B. pfeifferi Senegal and S. mansoni Senegal intermediate host/parasite relationship is much more compatible than that of $S$. mansoni Cameroon and B. pfeifferi Senegal. In fact, the analysis of the frequency of counts show that for $S$. mansoni Senegal/B. pfeifferi Senegal, $81 \%$ of the daily counts were over 200 , and $15.5 \%$ were over 1,000 cercariae per snail, compared with the $55 \%$ over 200 cercariae per snail and $8.6 \%$ over 1,000 cercariae per snail for $S$. mansoni Cameroon and $B$. pfeifferi Senegal. Data concerning infection rates, cercarial production, longevity of infected snails highlight the marked differences between the two intermediate host parasite combinations. It seems probable that the highly compatible host/parasite relationship that is evident between $B$. pfeifferi Senegal and $S$. mansoni Senegal as measured by infection rates, cercarial productivity, and longevity of infected snails is an important factor in providing an explanation for the extremely high prevalences and intensities of $S$. mansoni observed 
in the transmission foci of the Lower Valley of the SRB.

In addition to the introduction and spread of $S$. mansoni throughout much of the Lower and part of the Middle Valley of the SRB, there is evidence to show that $S$. haematobium is also spreading with levels of prevalence and intensity increasing on pre-dam levels (Verlé et al. 1994, Picquet et al. 1996). The increased levels of transmission are apparently correlated with the ecological changes which have been favourable to the spread of and increase in the size of the populations of $B$. globosus and $B$. senegalensis. B. globosus has benefited from the reduction in levels of salinity in the Senegal river, and $B$. senegalensis has colonised the newly created rice fields in the Middle Valley, for example, in the environs of Podor and Guédé Chantier. Recent data have demonstrated for the first time that isolates of S. haematobium originating from a number of foci between Diatar in the Middle Valley to the Senegal-Mali-Mauritanian border in the Upper Valley do show some compatibility with $B$. truncatus: these isolates are incompatible with B. globosus. Previous field and laboratory data (Southgate et al. 1985, Vercruysse et al. 1985, Picquet et al. 1996) indicated that $B$. truncatus was not involved in the epidemiology of urinary schistosomiasis in the SRB. Hence the reasons for the apparent change in the role of $B$. truncatus in the epidemiology of urinary schistosomiasis in the Middle Valley of the SRB are difficult to comprehend, but may be simply the result of an introduction of a compatible strain of S. haematobium from neighbouring Mali or indeed elsewhere in Africa. One disturbing observation is that $B$. truncatus is the most widespread bulinid species throughout the SRB, hence it is likely that there will be a significant increase in the levels of transmission of S. haematobium in the future. This new situation will be further exacerbated by the strains which are compatible with and transmitted by B. globosus and B. senegalensis: B. globosus is spreading throughout much of the Lower Valley as a result of the reduction in levels of salinity in the Senegal river. Observations in April 2000 showed B. globosus to be present in the Senegal river near Richard Toll, in the Taouey Canal, Ndombo and Lac de Guiers. B. senegalensis will continue to colonise the newly created habitats through the creation of new rice fields. As both S. haematobium and $S$. mansoni continue to spread through the SRB ever increasing numbers of people will have simultaneous infections of both species which may result in interspecific pairing and the production of parthenogenetic offspring. Recent studies by Webster et al. (1999) on mixed infections of $S$. mansoni and $S$. haematobium in hamsters showed that both heterospecific and homospecific pairs readily form, although $S$. mansoni showed a greater homospecific mate preference. Heterospecific pairs will mature, but the offspring will lack viability being parthenogenetic. Preliminary data showed that mating competition does occur between $S$. mansoni and S. haematobium, the latter being the dominant species, hence providing an explanation for Ernould's (1996) observations of S. mansoni eggs being passed in the urine of some people in the Lower Valley where the two species of parasite are sympatric.

\section{REFERENCES}

Belot J, Geerts S, Diouf M 1993. Observations on the population dynamics of snail hosts for schistosomes in the delta of the Senegal river basin. J Molluscan Studies 59: 7-13.

Chaine J-P, Malek EA 1983. Urinary schistosomiasis in the sahelian region of the Senegal river basin. Trop Geograph Med 35: 249-246.

Cisse E, Diallo S, Dieny M 1983. Bilan actuel de la bilharziose urinaire chez les populations riveraines du lac de Guiers. Dakar Médical 28: 343-350.

De Clercq D, Vercruysse J, Picquet M, Diop M, Ly A, Gryseels B 1999. The epidemiology of a recent focus of mixed Schistosoma haematobium and Schistosoma mansoni infection around the "lac de guiers" in the Senegal river basin, Senegal. Trop Med Int Health 4: 544-550.

Diaw OT, Vassilliades G, Seye M, Sarr Y 1990. Prolifération de mollusques et incidence sur les trématodoses dans la region du Delta et du Lac de Guiers aprés la construction du barrage de Diama sur le fleuve Sénégal. Bull Soc Franç Parasitol 2: 4-8.

Ernould JC 1996. Epidemiologie de schistosomes humains dans le delta du fleuve Senegal. Phenomene recent de competition entre Schistosoma haematobium (Bilharz, 1852) and Schistosoma mansoni Sambon 1907. PhD thesis, Université Paris XII, Val de Marne.

Miller MJ 1982. Parasites of man and arthropod disease vectors in communities of a water development program on the Senegal river basin. In E Meerovich. Aspects of Parasitology - A Feitschrift Dedicated to the Fiftieth Anniversary of the Institute of Parasitology of McGill University 1932-82, Institute of Parasitology, McGill University, Montreal, p. 279-334.

Picquet M, Ernould JC, Vercruysse J, Southgate VR, Mbaye A, Sambou B, Niang M, Rollinson D 1996. The epidemiology of human schistosomiasis in the Senegal river basin. Trans $R$ Soc Trop Med Hyg 9: 340-346.

Southgate VR 1997. Schistosomiasis in the Senegal river basin: before and after construction of the dams at Diama, Senegal and Manantali, Mali and future prospects. J Helminthol 71: 125-132.

Southgate VR, De Clercq D, Sène M, Rollinson D, Ly A, Vercruysse J 2000. Observations on the compatibility between Bulinus spp. and Schistosoma haematobium in the Senegal river basin. An Trop Med Parasitol 94: 157-164.

Southgate VR, Rollinson D, Ross GC, Knowles RJ, 
Vercruysse J 1985. On Schistosoma curassoni, S. haematobium and $S$. bovis from Senegal: development in Mesocricetus auratus, compatibility with species of Bulinus and their enzymes. J Nat Hist 19: 1249-1267.

Southgate VR, Tchuem Tchunté, L-A, Theron A, Jourdane J, Ly A, Moncrieff CB, Gryseels B 2000. Compatibility of Schistosoma mansoni Cameroon and Biomphalaria pfeifferi. Parasitology 121: 501505.

Talla I, Kongs A, Verlé P, Belot J, Sarr S, Coll AM 1990. Outbreak of intestinal schistosomiasis in the Senegal river basin. An Soc Belge de Méd Trop 70:173-180.

Talla I, Kongs A, Verlé P 1992. Preliminary study of the prevalence of human schistosomiasis in Richard-Toll (the Senegal river basin). Trans $R$ Soc Trop Med Hyg 86: 132.
Tchuem Tchuenté L-A, Southgate VR, Théron A, Jourdane J, Ly A, Gryseels B 1999. Compatibility of Schistosoma mansoni and Biomphalaria pfeifferi in Northern Senegal. Parasitology 118: 593-603.

Vercruysse J, Southgate VR, Rollinson D 1985. The epidemiology of human and animal schistosomiasis in the Senegal river basin. Acta Trop 42: 249-259.

Verlé P, Stelma F, Desreumaux P, Dieng A, Diaw O, Kongs A, Niang M, Sow S, Talla I, Sturrock RF, Gryseels B, Capron A 1994. Preliminary study of urinary schistosomiasis in a village in the delta of the Senegal river basin, Senegal. Trans $R$ Soc Trop Med Hyg 88: 401-405.

Webster BL, Southgate VR, Tchuem Tchuenté LA 1999. Mating interactions between Schistosoma haematobium and S. mansoni. J Helminthol 73: 351356. 